\title{
Assessment of Right Ventricular Function in Patients with Cor Pulmonale: Strain Imaging Study
}

\author{
Mohamed Elnoamany ${ }^{1}$, Tarek Khalil ${ }^{1}$, Ghada Soltan ${ }^{1}$, Naglaa Fahim ${ }^{1}$, Mohamed Omran ${ }^{2, *}$ \\ ${ }^{1}$ Cardiology Department, Faculty of Medicine, Menoufiya University, Menoufiya, Egypt \\ ${ }^{2}$ Cardiology Department, Ashmoun General Hospital, Menoufiya, Egypt
}

Email address:

mnoamany@hotmail.com (M. Elnoamany),dr.omran87@gmail.com (M. Omran)

${ }^{*}$ Corresponding author

\section{To cite this article:}

Mohamed Elnoamany, Tarek Khalil1, Ghada Soltan, Naglaa Fahim, Mohamed Omran. Assessment of Right Ventricular Function in Patients with Cor Pulmonale: Strain Imaging Study. Cardiology and Cardiovascular Research. Vol. 5, No. 3, 2021, pp. 147-152.

doi: $10.11648 /$ j.ccr.20210503.14

Received: August 20,2021; Accepted: September 1, 2021; Published: September 14, 2021

\begin{abstract}
Background: Cor pulmonale is one of the leading causes of heart failure. Speckle tracking echocardiography is a potential modality for evaluation of systolic and diastolic functions, myocardial mechanics and other cardiac pathophysiological processes. Objective: This study aims to assess the right ventricular (RV) function in patients with cor pulmonale using Strain Imaging and conventional echocardiography. Methods: Fifty patients with cor pulmonale compared to twenty age and sex matched controls selected for echocardiographic examination for assessment of RV indices; Pulmonary Artery Systolic Pressure (PASP), Tricuspid Annular systolic Excursion (TAPSE), Fractional Area Change (FAC), Tissue Doppler Imaging (TDI), Strain and Strain rate of RV free wall in addition to conventional left ventricular data. Results: TAPSE $(1.4 \pm 0.16$ vs $2.3 \pm 0.31 \mathrm{~cm})$, RV FAC $(30.5 \pm 4.3 \%$ vs $47.2 \pm 4.5 \%)$, PASP $(60.98 \pm 15.6$ vs $18.9 \pm 5.41 \mathrm{mmHg})$ and Systolic velocity of tricuspid annulus $\mathrm{S}^{\prime}(8.9 \pm 1.4 \mathrm{vs} 13.4 \pm 1.9 \mathrm{~cm} / \mathrm{sec})$ were significantly impaired in patients vs controls respectively with $p<0.001$ for all. Also, The global RV free wall peak systolic longitudinal strain ( $\varepsilon$ sys) for patients was $16.9 \pm 3.4 \%$ vs $25.2 \pm 2.9 \%$, The RV free wall systolic strain rate $\left(\mathrm{S}^{-1} \mathrm{~s}\right)$ was $0.98 \pm 0.18 \mathrm{vs} 1.7 \pm 0.18$, RV free wall early diastolic strain rate $\left(\mathrm{S}^{-1}\right.$ e) was $1.2 \pm 0.25$ vs $1.92 \pm 0.28$ and RV free wall late diastolic strain rate $\left(\mathrm{S}^{-1}\right.$ a) was $1.11 \pm 0.27$ vs $1.8 \pm 0.21$ with $(p<0.001$ for all). The RV free wall systolic Longitudinal Strain ( $\varepsilon$ sys) was negatively correlated with PASP $(\mathrm{r}=-0.950, p<0.001)$ and positively correlated with TAPSE, RV FAC and Systolic velocity of tricuspid annulus $\mathrm{S}^{\prime}(\mathrm{r}=0.635, \mathrm{r}=0.919, \mathrm{r}=0.890$ respectively with $p<0.001$ for all). Conclusion: Strain and Strain Rate are reliable tools to assess systolic and diastolic functions of the RV in patients with cor pulmonale even at early disease stages and correlate well with other conventional echo parameters for RV assessment.
\end{abstract}

Keywords: Cor Pulmonale, Right Ventricle, Strain, Strain Rate, Speckle Tracking

\section{Introduction}

Cor pulmonale is simply defined as "right ventricular hypertrophy, dilation, or both caused by primary pulmonary disorders [1]." Approximately $15 \%$ to $20 \%$ of all heart failure patients and $7 \%$ to $10 \%$ of all heart disease are caused by cor pulmonale [2]. Smoking men between the ages of 50 and 60 are more commonly affected [3], COPD is far away the most common etiology of chronic Cor pulmonale in the developed countries [2].

$\mathrm{RV}$ assessment is challenging due to multiple factors including: The complex geometry, heavy myocardial trabeculations and the retrosternal location of the RV, which can interfere echocardiographic imaging windows [4]. Cardiac MRI is believed to be the standard accurate tool in the assessment of RV structure and function with $90 \%$ sensitivity and $85 \%$ specificity [5] but when come to clinical application, echocardiography is the mainstay of assessment of RV structure and function because it provide the advantages of versatility and availability over other modalities [6]. Speckle tracking is a hopeful imaging modality as it enables calculation of myocardial velocities and deformation parameters such as strain and strain rate 
offline, thus, providing valuable information about myocardial mechanics, systolic and diastolic functions, ischemia and many other pathophysiological aspects of the heart [7].

\section{Patients and Methods}

This cross-sectional, observational study was done at cardiology department of Menoufiya University Hospital. The study was carried out on Seventy (70) volunteers who were divided into two groups:

Group I: Fifty (50) patients with Cor pulmonale diagnosed clinically in addition specific echocardiographic features.

Group II: Twenty (20) age and sex matched subjects as a control group.

Transthoracic echocardiographic examination was done with a simultaneous ECG signaling. The following parameters were evaluated:

Conventional LV parameters; including: Aortic (AO) and left atrial diameters (LA), IVS and LV posterior wall thickness (LVPW), Left ventricular diameter at diastole (LVEED) and at systole (LVESD), LV systolic function (LVEF\%), Mitral inflow velocity at early diastole (E) and at late diastole (A) and subsequent calculation of $\mathrm{E} / \mathrm{A}$ ratio.

Right Ventricular Parameters; including: Quantitative assessment of the basal RV End Diastolic Dimension (RVEDD), right ventricular Fractional Area Change (FAC), Tricuspid annular plane systolic excursion (TAPSE), Assessment of PASP by calculating the maximum velocity of the tricuspid regurgitation jet using Bernolli equation: $\left[\mathrm{RVSP}=4\right.$ (Velocity) ${ }^{2}+$ RA pressure] [8], Tricuspid inflow velocity at early diastole (E) and at late diastole (A) and subsequent calculation of E/A ratio [9].

Tissue Doppler Imaging: Tricuspid annulus longitudinal velocity of excursion ( $\left.\mathrm{S}^{\prime}\right)$, Early and Late diastolic velocity of the tricuspid annulus ( $\left.\mathrm{E}^{\prime}, \mathrm{A}^{\prime}\right), \mathrm{E} / \mathrm{E}^{\prime}$ is calculated.

Speckle Tracking Echocardiography: Assessment of global and segmental peak systolic longitudinal Strain ( $\mathcal{E}$ sys) of RV free wall. Assessment of average value of the peak systolic Strain rate $\left(\mathrm{S}^{-1} \mathrm{~s}\right)$, peak early diastolic Strain Rate $\left(\mathrm{S}^{-1} \mathrm{e}\right)$, and peak late diastolic Strain rate $\left(\mathrm{S}^{-1}\right.$ a) at each segment (basal, mid and apical) of the RV free wall were measured.

In this study, all variables represent the mean value of measurements calculated in 3 successive cardiac cycles.

\section{Statistical Analysis}

Using SPSS statistical package version 23, data from the patients and controls were collected and subjected to statistical analysis. Tables and graphs were used to show the various observations, together with an explanation of the most important findings. Mean $\pm \mathrm{SD}$ was calculated and chisquare test was applied. When it comes to statistical significance, $P$ value of $\leq 0.05$ was considered as statistically significant, a value of $\leq 0.01$ as very significant while a value of $\leq 0.001$ as highly significant.

\section{Results}

As regard demographic data, no difference could be detected for age, sex, DM, or Hypertension between Patients and controls, but the percentage of smokers in patients was significantly greater $(53.2 \%)$ than those in controls $(25 \%)$ with $p=0.034$. LV parameters shows no significant difference between patients and the controls except for LV diastolic function (Mitral E/A was $0.62 \pm 0.21$ for patients and $0.98 \pm 0.42$ for control with $p=0.002$ ).

Table 1. Right Ventricle parameters of studied subjects.

\begin{tabular}{|c|c|c|c|c|}
\hline & Group 1 (cases) no=50 & Group 2 (control) no=20 & T test & P value \\
\hline TAPSE $(\mathrm{cm})$ & $1.4 \pm 0.16$ & $2.3 \pm 0.31$ & 14.751 & $<0.001 * *$ \\
\hline RV FAC $\%$ & $30.5 \pm 4.3$ & $47.2 \pm 4.5$ & 14.003 & $<0.001 * *$ \\
\hline PASP (mmHg) & $60.98 \pm 15.6$ & $18.9 \pm 5.41$ & 12.101 & $<0.001 * *$ \\
\hline RVEDD (mm) & $40 \pm 4$ & $31 \pm 6$ & 3.452 & $<0.001 * *$ \\
\hline $\mathrm{S}^{\prime}(\mathrm{cm} / \mathrm{sec})$ & $8.9 \pm 1.4$ & $13.4 \pm 1.9$ & 10.01 & $<0.001 * *$ \\
\hline Tri E $(\mathrm{cm} / \mathrm{s})$ & $46.9 \pm 12.21$ & $51.61 \pm 10.20$ & 1.823 & $0.002 *$ \\
\hline Tri E/A & $0.62 \pm 0.23$ & $0.94 \pm 0.42$ & 3.722 & $0.001 *$ \\
\hline Tri E/E' & $7.08 \pm 1.11$ & $4.27 \pm 0.89$ & 10.23 & $<0.001 * *$ \\
\hline
\end{tabular}

**: p-value $<0.001=$ highly significant; *: p-value $<0.05=$ significant; TAPSE: Tricuspid annular plane systolic excursion; RV FAC: Right Ventricle Fractional Area Change; PASP: Pulmonary Artery Systolic Pressure; RVEDD: Right Ventricle End Diastolic diameter; S': Systolic velocity of tricuspid annulus; TV E: Tricuspid flow velocity at early diastole; TV A: Tricuspid flow velocity at late diastole; E': Early diastolic velocity of the tricuspid annulus; A': Late diastolic velocity of the tricuspid annulus.

All Right Ventricular parameters (table 1) were significantly impaired in patients, TAPSE was $(1.4 \pm 0.16$ vs $2.3 \pm 0.31 \mathrm{~cm})$, RV FAC was $(30.5 \pm 4.3 \%$ vs $47.2 \pm 4.5 \%)$, PASP was $(60.98 \pm 15.6$ vs $18.9 \pm 5.41 \mathrm{mmHg}), \mathrm{RV}$ end diastolic diameter (RVEDD) was (40 \pm 4 vs $31 \pm 6 \mathrm{~mm})$ and Systolic velocity of tricuspid annulus (S') was $(8.9 \pm 1.4$ vs $13.4 \pm 1.9 \mathrm{~cm} / \mathrm{sec}$ ) for patients vs controls respectively with $p<0.001$ for all. Also, parameters of RV diastolic function were impaired in patients, Early diastolic Tricuspid flow velocity (E) for patients was $(46.9 \pm 12.21 \mathrm{~cm} / \mathrm{sec}$ and $51.61 \pm 10.20 \mathrm{~cm} / \mathrm{sec}$ for control with $p=0.002)$, Early diastolic velocity of the tricuspid annulus ( $\left.E^{\prime}\right)$ was $(6.5 \pm 1.7$ $\mathrm{cm} / \mathrm{sec}$ in patients vs $12.4 \pm 3.9 \mathrm{~cm} / \mathrm{sec}$ in controls with $p<0.001$ ) while Tricuspid E/A was $0.62 \pm 0.23$ for patients vs $0.94 \pm 0.42$ for controls with $p=0.001$ and $\mathrm{E} / \mathrm{E}^{\prime}$ was $7.08 \pm 1.11$ in patients vs $4.27 \pm 0.89$ in controls with $p<0.001$. 
Table 2. Right ventricular free wall peak longitudinal systolic strain ( $\varepsilon$ sys\%) and strain rate $\left(S^{-1}\right)$ of the studied groups.

\begin{tabular}{lllll}
\hline & Group 1 (cases) no=50 & Group 2 (control) no=20 & T test & P value \\
\hline Basal $(\varepsilon$ sys\%) & $16.4 \pm 2.16$ & $24.3 \pm 6.31$ & 7.325 & $<0.001^{* *}$ \\
Mid $(\varepsilon$ sys\%) & $17.5 \pm 3.3$ & $27.2 \pm 2.5$ & 11.043 & $<0.001^{* *}$ \\
Apical $(\varepsilon$ sys\%) & $16.98 \pm 3.6$ & $25.9 \pm 2.41$ & 10.211 & $<0.001^{* *}$ \\
Global $(\varepsilon$ sys\%) & $16.90 \pm 3.4$ & $25.2 \pm 2.9$ & 11.140 & $<0.001^{* *}$ \\
$\mathrm{~S}^{-1} \mathrm{~s}$ & $1.08 \pm 0.19$ & $1.7 \pm 0.18$ & 12.140 & $<0.001^{* *}$ \\
$\mathrm{~S}^{-1} \mathrm{e}$ & $1.2 \pm 0.25$ & $1.92 \pm 0.28$ & 9.320 & $<0.001^{* *}$ \\
$\mathrm{~S}^{-1} \mathrm{a}$ & $1.11 \pm 0.27$ & $1.8 \pm 0.21$ & 9.230 & $<0.001^{* *}$ \\
\hline
\end{tabular}

**: $p$-value $<0.001=$ highly significant; *: p-value $<0.05=$ significant. $\varepsilon$ sys\%: Peak systolic longitudinal strain; $S^{1} s$ : Strain rate at Systole; $S^{-1} e$ : Strain rate at early diastole; $S^{-1}$ a: Strain rate at late diastole

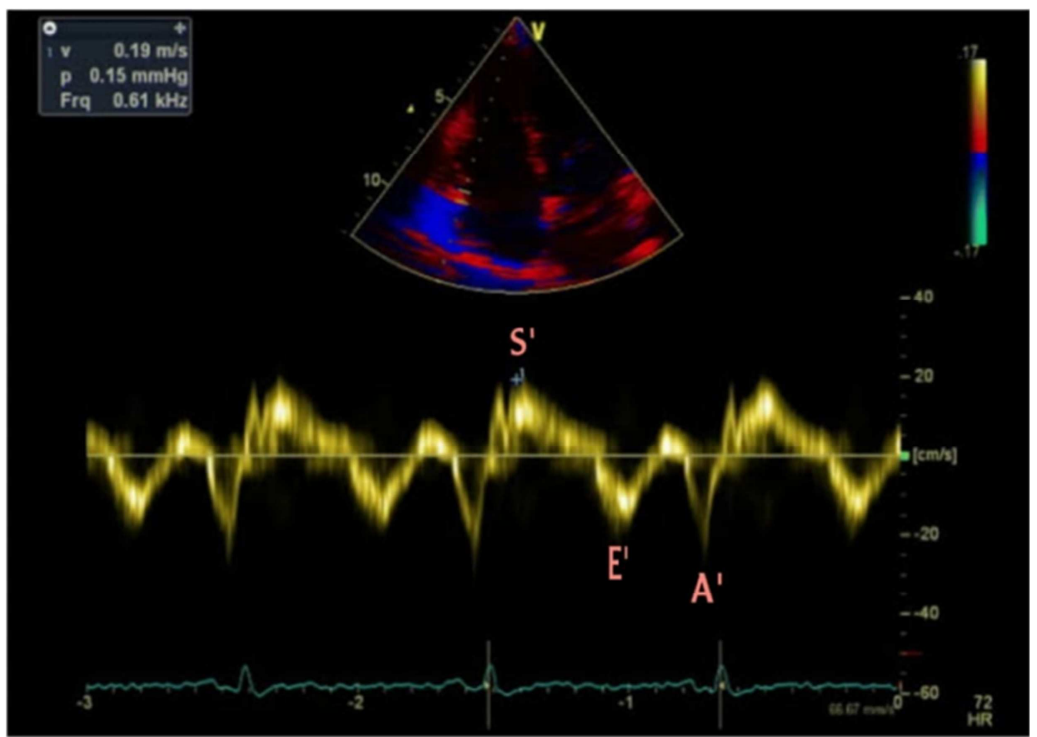

Figure 1. Tissue Doppler of the lateral tricuspid annulus; S': Systolic Velocity of lateral tricuspid annulus; E': Early diastolic Velocity of lateral tricuspid annulus; A': Late diastolic Velocity of lateral tricuspid annulus.
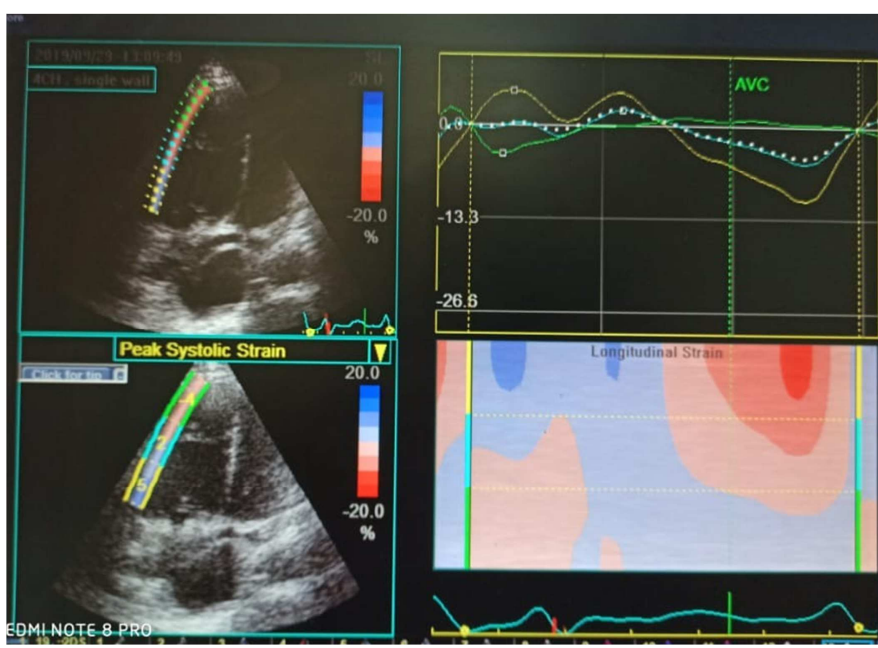

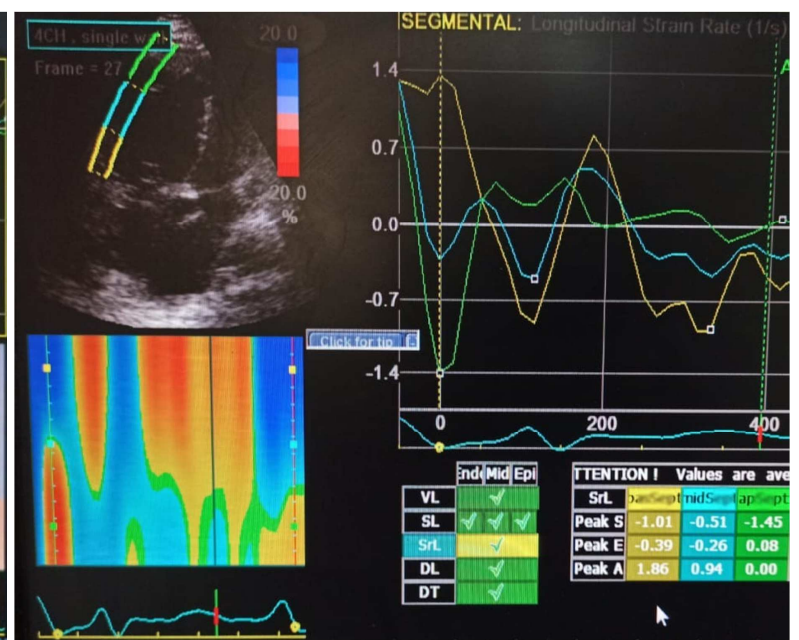

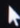

Figure 2. Strain and Strain Rate of the RV free wall.

As shown in Table 2, the global and segmental peak longitudinal systolic Strain ( $\varepsilon$ sys) of RV free wall were significantly reduced in the patient group. Basal segment $\varepsilon$ sys was $(16.4 \pm 2.16 \%$ vs $24.3 \pm 6.31 \%)$, Mid segment $\varepsilon$ sys was $(17.5 \pm 3.3 \%$ vs $27.2 \pm 2.5 \%)$, Apical $\varepsilon$ sys was $(16.98 \pm 3.6 \%$ vs $25.9 \pm 2.41 \%)$ and the global RV free wall longitudinal strain was $(16.90 \pm 3.4 \%$ vs $25.2 \pm 2.9 \%)$ for patients vs controls respectively with $p<0.001$ for all.

Strain rate $\left(\mathrm{S}^{-1}\right)$ data of $\mathrm{RV}$ free wall of studied groups in Table 2 revealed significant differences among the 2 groups. $\mathrm{RV}$ free wall systolic strain rate $\left(\mathrm{S}^{-1} \mathrm{~s}\right)$ was $(1.08 \pm 0.19 \mathrm{vs}$ $1.7 \pm 0.18)$, RV free wall early diastolic strain rate at $\left(\mathrm{S}^{-1} \mathrm{e}\right)$ was $(1.2 \pm 0.25$ vs $1.92 \pm 0.28)$, RV free wall late diastolic strain rate $\left(\mathrm{S}^{-1}\right.$ a) was $(1.11 \pm 0.27$ vs $1.8 \pm 0.21)$ for patients vs 
controls respectively with $p<0.001$ for all.
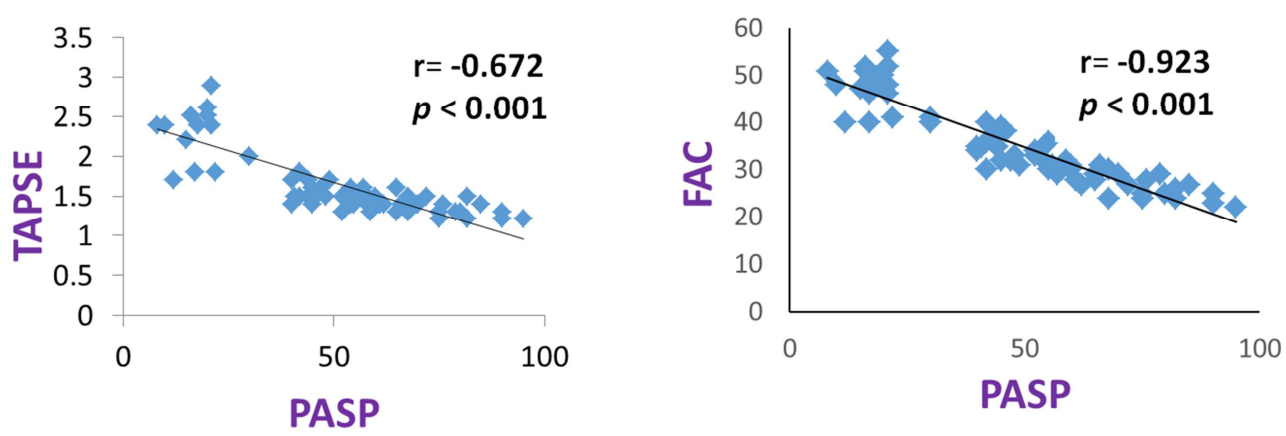

Figure 3. Correlation between PASP and (TAPSE \& RV FAC).

Also, the study shows significant correlations demonstrated as follow; PASP has statistically significant Negative correlations with TAPSE $(\mathrm{r}=-0.672, p<0.001)$ and RV FAC $(\mathrm{r}=-0.923, p<0.001)$ as shown in figure 3.
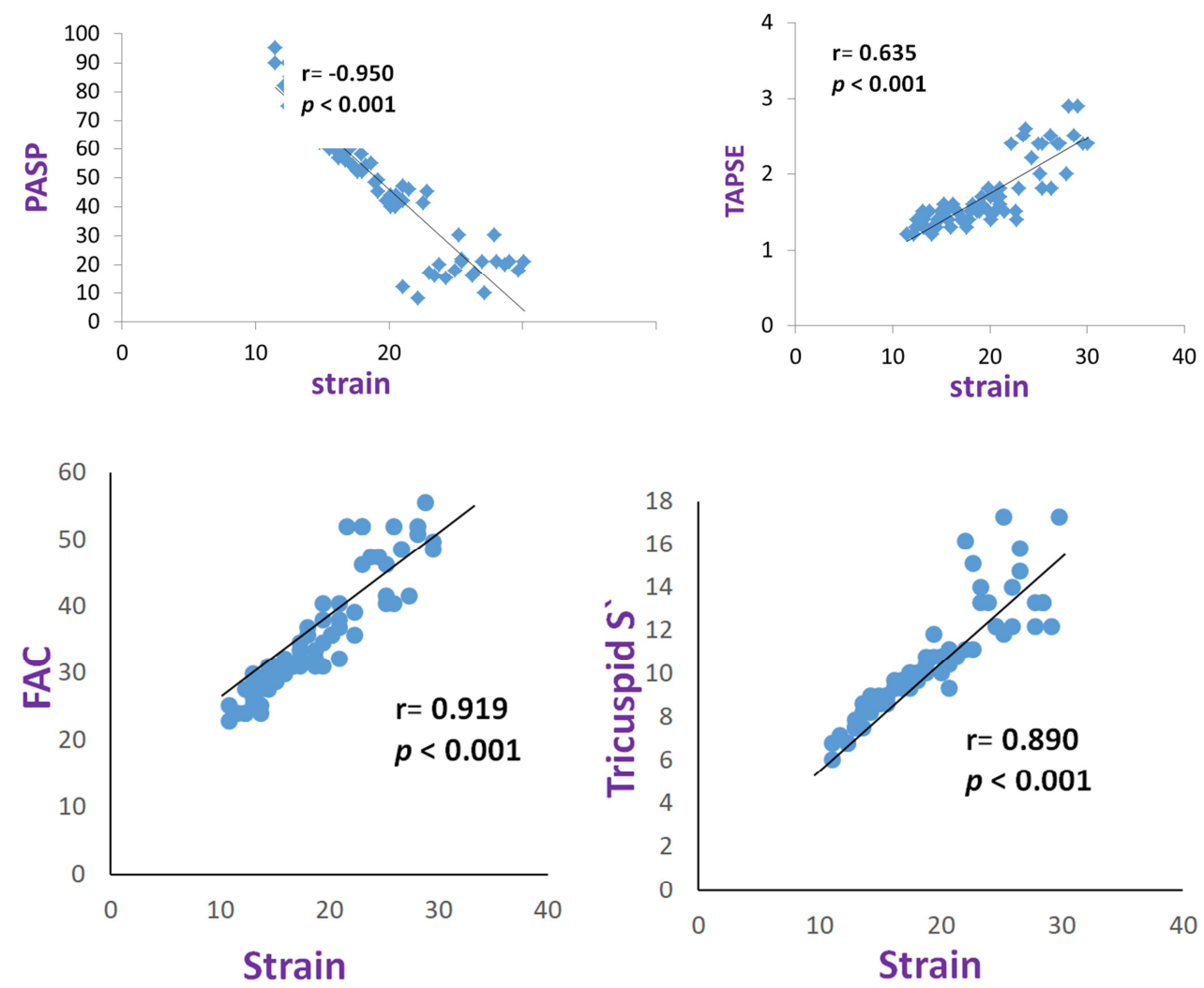

Figure 4. Correlation between RV free wall strain and (PASP, TAPSE, RV FAC and Tricuspid $S^{\prime \prime}$ ).

While Figure 4 shows that RV free wall systolic Longitudinal Strain was negatively correlated with PASP ( $\mathrm{r}=$ $0.950, p<0.001)$ and positively correlated with both TAPSE, RV FAC and Tricuspid annular systolic velocity (S') $(\mathrm{r}=0.635, \mathrm{r}=0.919, \mathrm{r}=0.890$ respectively with $p<0.001$ for all).

\section{Discussion}

In the current study, Two-dimensional (2D) speckletracking echocardiography was used to assess RV functions. This method overcomes angle dependence, allowing quantitative recording od RV longitudinal motion [10]. Our study revealed that speckle-tracking echocardiography of RV longitudinal deformation may play a very important diagnostic roles in patients with cor pulmonale. This novel index complements traditional echocardiographic parameters and shows strong correlations with severity of pulmonary disease.

Regarding the right ventricular parameters, the current study showed that PASP was significantly elevated in patients $(60.98 \pm 15.6 \mathrm{mmHg}$ vs $18.9 \pm 5.41 \mathrm{mmHg})$ while TAPSE $(1.4 \pm 0.16$ vs $2.3 \pm 0.31 \mathrm{~cm})$, RV FAC $(30.5 \pm 4.3 \%$ vs $47.2 \pm 4.5 \%)$ and Tricuspid S' $(8.9 \pm 1.4$ vs $13.4 \pm 1.9 \mathrm{~cm} / \mathrm{sec})$ were significantly depressed in patients compared to controls 
with $p<0.001$ for all. Those data were supported by Gupta $K K$ et al [11] whose study included 109 COPD patients, PASP was $37.5 \pm 1.2 \mathrm{mmHg}$ in mild cases and reach to $68.3 \pm 4.6 \mathrm{mmHg}$ in severe cases with $p<0.001$. Lettieri et al [12] study on patients with interstitial lung diseases supported our results, their mPAP for patients was $29.5 \pm 3.3$ vs $19.1 \pm 3.7 \mathrm{~mm} \mathrm{Hg}$ for normal subjects with $p<0.001$. Meris et al [13] that studied 100 healthy individuals and 76 patients with RV dysfunction came to similar results, TAPSE was $1.4 \pm 0.3$ vs $2.5 \pm 0.4$ while RV FAC was $31 \pm 7 \%$ vs $45 \pm 6 \%$ for patients vs controls respectively with $p<0.001$. Forfia et al [14] results on patients with pulmonary hypertension, FAC and TAPSE were significantly impaired $(30 \pm 13 \%$ \& $1.9 \pm 0.6$ $\mathrm{cm}$ respectively). Also, similar results by Sato, et al [15], that studied 37 consecutive patients with PH found that TAPSE $(19 \pm 4 \mathrm{~mm}), \mathrm{RV}$ FAC $(31 \pm 17 \%)$ and Tricuspid $\mathrm{S}^{\prime}(9.3 \pm 2.4$ $\mathrm{cm} / \mathrm{sec}$ ) were significantly impaired and correlated with CMRI-derived RVEF (FAC: $r=0.40, p=0.0083$; TAPSE: $r=0.86, p<0.0001$, Tricuspid $\left.\mathrm{S}^{\prime}: r=0.63, p<.0001\right)$.

This study also demonstrated s significant impairment of $\mathrm{RV}$ diastolic function as there was a statistically significant difference between the 2 groups as regard Tricuspid E/A $(p=0.001)$, Tricuspid E'/A' $(p<0.001)$ and Tricuspid E/E' $(p<0.001)$. This is similar to Özer et al [16] who showed that patients with COPD and pulmonary hypertension had left and right ventricular diastolic dysfunction.

2D Speckle tracking evaluation of the RV free wall in our study showed significant impairment of global and segmental longitudinal systolic strain and strain rate in patients compared to control subjects. The global peak systolic longitudinal strain ( $\varepsilon$ sys) for patients was $(16.9 \pm 3.4 \%$ vs $25.2 \pm 2.9 \%)$, The RV free wall systolic strain rate $\left(S^{-1} s\right)$ was $(0.98 \pm 0.18$ vs $1.7 \pm 0.18)$, RV free wall early diastolic strain rate at $\left(S^{-1} e\right)$ was $(1.2 \pm 0.25$ vs $1.92 \pm 0.28)$ with $(p<0.001)$ and RV free wall late diastolic strain rate $\left(S^{-1}\right.$ a) was $(1.11 \pm 0.27$ vs $1.8 \pm 0.21)$ with $(p<0.001$ for all).

These findings are supported by other studies such as $L i$, Yuman, et al [17] who explored that global and segmental RV longitudinal peak systolic strain ( $\varepsilon$ sys $\%)$ and strain rate $\left(\mathrm{S}^{-1}\right)$ of the RV free wall and septum were significantly impaired in patients of PAH compared with controls $(p<0.05$ for all). RV Global Longitudinal Strain was further reduced in severe PAH group (14.22 $\pm 4.93 \%$ in severe PAH vs. $20.52 \pm 5.60 \%$ in mild PAH with $p<0.05)$. Similar results found by Calcutteea et al [18], who studied 35 patients with pulmonary hypertension compared to 20 controls and found that patient group showed significant reduction in strain rate of basal segment $(1.4 \pm 0.6$ vs $1.9 \pm 0.5)$ and mid-segment $(1.7 \pm 0.4$ vs $1 \pm 0.4)$ with $p<0.001$ for all. Also, there was reduced peak systolic strain at multiple right ventricle levels: basal (14.8 \pm 6.7$)$ and mid (12.1 \pm 6.2$)$ segments and RVOT (7.1 \pm 4.8$)$ with $p<0.001$ for all. Also, Vitarelli, A., et al [19] study on COPD patients, Strain and strain rate $\left(S^{-1}\right)$ values were decreased in all RV segments of patients compared with controls. Peak longitudinal strain was (19.5 \pm 7.9 vs $32.5 \pm 10.2, p<0.001)$ Systolic Strain rate $S^{-1} s$ was $(2.9 \pm 1.5$ vs $4.9 \pm 1.8, p<0.001)$ early diastolic Strain rate $\left(S^{-1} e\right)$ was

\section{(4.4 \pm 1.7 vs $8.4 \pm 1.8, p<0.05)$.}

The present study showed some significant correlations; $P A S P$ has a statistically significant Negative correlations with TAPSE and RV FAC, while RV free wall Longitudinal Strain $(\varepsilon$ sys) had a significant negative correlation with $P A S P$ and a significant positive correlation with TAPSE, Tricuspid $S^{\prime}, R V$ FAC $(p<0.001$ for all). These results were similar to Elnoamany et al [20] study on patients with pulmonary hypertension and showed that TAPSE, RV Strain and strain rate are significantly depressed with increasing PASP ( $r=$ $0.552, \mathrm{r}=-0.659, r=-0.626$ respectively and $p<0.001$ for all). $L i$, Yuman, et al [17] supported our results and revealed a strong correlation between PASP and RV Global Longitudinal Strain and Strain Rate $\left(r_{l}=-0.551 ; r_{2}=-0.425\right.$, respectively, $p<0.05$ for both). Also, Meris et al [13] found a significant correlation between RV Peak Longitudinal Strain and Tricuspid Annular Plane Systolic Excursion $(r=-0.83, p<0.001)$.

\section{Study Limitations}

Despite the fact that our results were in line with past research, our study faced some limitations: First; the small number of patients involved. Second; tracing of endocardial border of the RV wall necessitates special care when manually fine-tuning the regions of interest before measuring regional strain. Third; our results was not compared with those of cardiac MRI and PASP was not measured by invasive methods. Fourth; RV strain was evaluated only in the apical 4-chamber view of the three RV free wall segments. Finally, the optimal peak systolic strain cut-off value for differentiating normal and impaired RV systolic function was not validated in an independent sample.

\section{Conclusions}

Speckle Tracking Echocardiography; Strain and Strain Rate are a reliable tools to assess the RV functions as it correlates well with other more established parameters of global RV systolic function (ie, TAPSE and RV FAC). Furthermore, regional RV Strain enables to study regional $\mathrm{RV}$ function, therefore can be used as an index of RV function in patients with cor pulmonale with a great diagnostic value and allow better management of patients right ventricular dysfunction.

\section{Recommendations}

The present study recommends: First; future research involving a large number of patients are required to validate the above findings and focus light on this critical issue. Second; assessment of the RV systolic and diastolic functions must be performed on every patient with chronic respiratory problems. Third; cor pulmonale patients should be evaluated by strain \& strain rate echocardiography as part of their routine assessment. Fourth; more effort required in the near future to solve the technical issues and pitfalls associated with strain and strain rate imaging. 


\section{References}

[1] Niederman M, Matthay RA. Cardiovascular function in secondary pulmonary hypertension. Heart \& Lung. 1986: 15: $341-51$

[2] MacNee W. Pathophysiology of cor pulmonale in chronic obstructive pulmonary disease. Part One. American journal of respiratory and critical care medicine. 1994; $150(3): 833-52$.

[3] MacNee W. Pathophysiology of cor pulmonale in chronic obstructive pulmonary disease. Part two. American journal of respiratory and critical care medicine. 1994; 150 (4): 1158-68.

[4] Jiang L, Levine RA, Weyman AE. Echocardiographic assessment of right ventricular volume and function. Echocardiography. 1997; 14 (2): 189-205.

[5] Jiang L, Wiegers S, Weyman A. Right ventricle. Principles and practice of echocardiography 2 nd ed Philadelphia: Lea \& Febiger. 1994: 901-21.

[6] Haddad F, Hunt SA, Rosenthal DN, Murphy DJ. Right ventricular function in cardiovascular disease, part I: anatomy, physiology, aging, and functional assessment of the right ventricle. Circulation. 2008; 117 (11): 1436-48.

[7] Artis N, Oxborough D, Williams G, Pepper C, Tan L. Twodimensional strain imaging: a new echocardiographic advance with research and clinical applications. International journal of cardiology. 2008; 123 (3): 240-8.

[8] Chan K-L, Currie PJ, Seward JB, Hagler DJ, Mair DD, Tajik AJ. Comparison of three Doppler ultrasound methods in the prediction of pulmonary artery pressure. Journal of the American College of Cardiology. 1987; 9 (3): 549-54.

[9] Picard MH, Adams D, Bierig SM, Dent JM, Douglas PS, Gillam LD, Keller AM, Malenka DJ, Masoudi FA, McCulloch M. American Society of Echocardiography recommendations for quality echocardiography laboratory operations. Journal of the American Society of Echocardiography. 2011; 24 (1): 110 .

[10] Luo A, Yin L, Chun-Mei L, Wang L, Lin J, Cai Y, Meng Q. Measurement of left ventricular torsion with cardiac pacing and right bundle branch block patients by two-dimensional ultrasound speckle tracking imaging. Chinese J Ultrasonography. 2006; 15.

[11] Gupta KK, Roy B, Chaudhary SC, Mishra A, Patel M, Singh J, Kumar V. Prevalence of pulmonary artery hypertension in patients of chronic obstructive pulmonary disease and its correlation with stages of chronic obstructive pulmonary disease, exercising capacity, and quality of life. Journal of family medicine and primary care. 2018; 7 (1): 53.

[12] Lettieri, CJ, Nathan, SD, Barnett, SD, Ahmad, S, Shorr, AF. Prevalence and outcomes of pulmonary arterial hypertension in advanced idiopathic pulmonary fibrosis. Chest 2006: 129: $746-52$.

[13] Meris A, Faletra F, Conca C, Klersy C, Regoli F, Klimusina J, Penco M, Pasotti E, Pedrazzini GB, Moccetti T. Timing and magnitude of regional right ventricular function: a speckle tracking-derived strain study of normal subjects and patients with right ventricular dysfunction. Journal of the American Society of Echocardiography. 2010; 23 (8): 823-31.

[14] Forfia PR, Fisher MR, Mathai SC, Housten-Harris T, Hemnes AR, Borlaug BA, Chamera E, Corretti MC, Champion HC, Abraham TP. Tricuspid annular displacement predicts survival in pulmonary hypertension. American journal of respiratory and critical care medicine. 2006; 174 (9): 1034-41.

[15] Sato T, Tsujino I, Ohira H, Oyama-Manabe N, Yamada A, Ito YM, Goto C, Watanabe T, Sakaue S, Nishimura M. Validation study on the accuracy of echocardiographic measurements of right ventricular systolic function in pulmonary hypertension. Journal of the American Society of Echocardiography. 2012; 25 (3): $280-6$

[16] Özer N, Tokgözoğlu L, Çöplü L, Kes S. Echocardiographic evaluation of left and right ventricular diastolic function in patients with chronic obstructive pulmonary disease. Journal of the American Society of Echocardiography. 2001; 14 (6): 557-61.

[17] Li Y, Xie M, Wang X, Lu Q, Fu M. Right ventricular regional and global systolic function is diminished in patients with pulmonary arterial hypertension: a 2-dimensional ultrasound speckle tracking echocardiography study. The International Journal of Cardiovascular Imaging. 2013; 29 (3): 545-51.

[18] Calcutteea A, Lindqvist P, Soderberg S, Henein MY. Global and regional right ventricular dysfunction in pulmonary hypertension. Echocardiography. 2014; 31 (2): 164-71.

[19] Vitarelli A, Conde Y, Cimino E, Stellato S, D'orazio S, D'angeli I, Nguyen B, Padella V, Caranci F, Petroianni A. Assessment of right ventricular function by strain rate imaging in chronic obstructive pulmonary disease. European Respiratory Journal. 2006; 27 (2): 268-75.

[20] Elnoamany MF, Ahmed NF, Ragab EMS. Echocardiographic assessment of right ventricular function in patients with pulmonary hypertension: strain imaging study. Menoufia Medical Journal. 2014; 27 (2): 336. 